\title{
Epidemiological and Genetical Studies in Norwegian Pig Herds
}

\section{Design of a Disease Recording System}

\author{
By Frode Lingaas and Knut Ronningen \\ Department of Animal Genetics, \\ Norwegian College of Veterinary Medicine, Oslo, Norway.
}

\begin{abstract}
Lingaas, F. and K. Ronningen: Epidemiological and genetical studies in Norwegian pig herds. I. Design of a disease recording system. Acta vet. scand. 1990, 31, 243-249. - The study was based on 70 pig herds in the south-eastern part of Norway during the period from 1984 to 1986 . The purpose was to design a health card system based on individual disease records covering diseases in sows, piglets and slaughter pigs. It is concluded that individual health records on a herd basis may well be suited for use in epidemiological and genetical studies of disease frequencies and disease resistance. Feedback of results to farmers and veterinarians seems to be important for satisfactory follow-up in the herds.
\end{abstract}

swine; diseases; preventive veterinary medicine; health cards.

\section{Introduction}

Sufficient information on disease patterns in livestock is a prerequisite for adequate disease control at the herd level. A system for recording diseases would therefore be of help in disease control in pig herds. Individual health recording has been performed with good experiences in Norwegian cattle (Solbu 1983), but the authors are not aware of any earlier studies based on individual health records in Norwegian pig populations. A system of disease recording in pigs based on health cards was evaluated in a project started in Hedmark county in the end of 1983. In Hedmark combined pig and grain farming is a common husbandry practice. The purpose of the project was to perform epidemiological and genetical studies in the pig herds, and to design a suitable health card for practical use in the herds. This paper will mainly deal with the practical problems associated with disease recording, feed-back routines and use of disease records.

\section{Material and methods}

Disease recordings

In 1983 disease recording was started in 70 herds in which herd performance was already being recorded (Anon. 1986). Animals used for breeding were marked with individual numbers for identification purposes, and performance criteria such as the number of piglets born (dead/alive), number of piglets alive at 3 weeks etc., were recorded and reported to a central unit. The mean number of sows was 25 in the investigated herds, which is somewhat higher than the overall mean of herds on recording performance in Norway $(n=18)$. Two different types of health cards were produced, one type being distributed to half of the farms and the other type to the other half. One type, the "individual card", was designed as an individual card for each sow, similar to the one used with dairy cattle (Solbu 1983). The second type, the "herd card" (Fig. 1a), was designed for individual entries on a single herd card. 


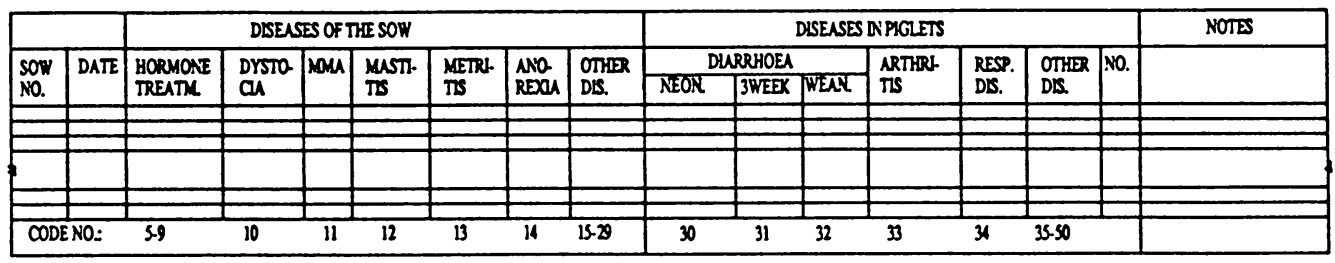

Figure 1a. The herd health card used in the disease recording project. All disease codes are shown in Table 1.

Both designs included separate columns for the most common diseases, while less frequent diseases had number-codes. Recorded diseases and disease codes are given in Table 1 .

The herds were visited 4 times a year by the same person. Disease-records and information on performance, management and hygiene was collected.

\section{Disease reports}

Disease frequencies were expressed as "Number of treatments per 100 sows during one year" and derived in the following way:

No. of rec. treatments $\times 100 \times 365$

No. of sows in the herd $\times$ Period length in days

Disease reports were sent to farmers and veterinarians. The farmers were notified of the disease frequency in their own herd compared to the overall disease frequency. This information was given for the previous 3-month-period and for the previous year. The veterinarians received reports on all herds.

\section{Evaluation by farmers and veterinarians}

In connection with any health card system it is important to know the extent to which the different disease-categories are actually reported. Questionnaires were sent to all the 70 farmers and the 10 veterinarians who had participated in the project, to get an evaluation of the health card system.

\section{Results}

The herd card was preferred over the individual card by both farmers and veterinarians. An important disadvantage of the individual card is that in large pig herds, there was a rapid accumulation of considerable numbers of cards due to the high turnover rate of animals. It is also the view of both veterinarians and farmers that the herd card gave the best overview of herd disease problems. The percentage of diseases recorded on the herd cards also tended to be higher than on the individual cards.

Disease recording on an individual basis may be hampered by poor identification systems. In most herds participating in the

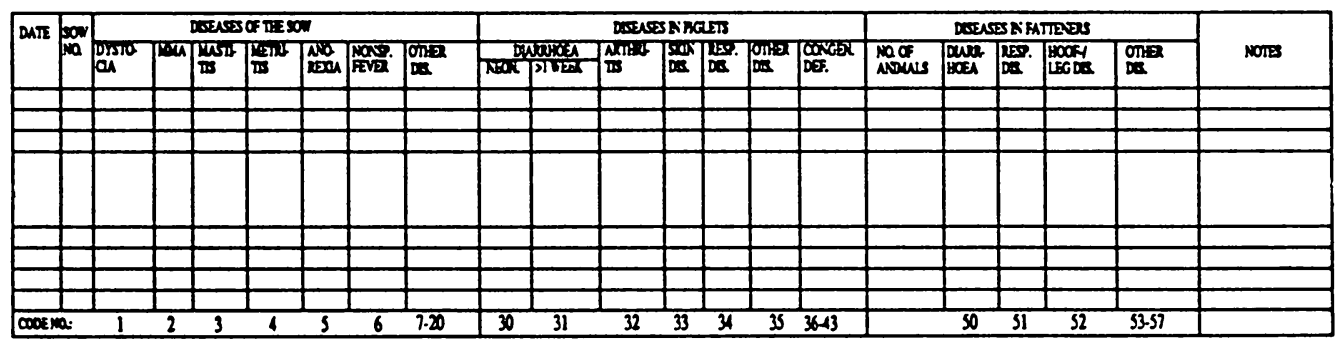

Figure $1 \mathrm{~b}$. The herd health card recommended for future use. All disease codes are shown i Table 2. 
Table 1. Diseases recorded in the project on health cards in pigs.

Hormone treatment of the sow

Code 5. HCG + Oestradiol

Code 6. HCG + PMSG

Code 7. Prostaglandines for birth induction

Code 8. Other hormone treatments

Diseases of the sow

Code 10. Dystocia

Code 11. MMA-syndrome

Code 12. Mastitis

Code 13. Metritis

Code 14. Unspecific reduced appetite

Code 15. Abscesses/phlegmons

Code 16. Agalactia

Code 17. Diarrhoea

Code 18. Abortion

Code 19. Hoof/joint diseases

Code 20. Deficiency diseases

Code 21. Respiratory diseases

Code 22. Erysipelas

Code 23. Skeletal/muscular disease

Code 24. Urinary tract diseases

Code 25. Non-specific fever

Code 26. Other diseases

Diseases in piglets

Recorded by the veterinarian

Code 30. Neonatal diarrhoea

Code 31. 3-week diarrhoea

Code 32. Diarrhoea at weaning

Code 33. Arthritis

Code 34 . Respiratory diseases

Code 35. Skin diseases

Code 36. Deficiency diseases

Code 37. Trauma/injury

Code 38. Other diseases

Recorded by the farmer

Code 39. Splay-leg

Code 40. Cryptorchism

Code 41. Atresia ani

Code 42. Umbilical hernia

Code 43. Scrotal hernia

Code 44. Shivering

Code 45. Hermaphrodism
Table 2. The recommended health card.

\author{
Diseases of the sow \\ Code 1. Dystocia \\ Code 2. MMA-syndrome \\ Code 3. Mastitis \\ Code 4. Metritis \\ Code 5. Anorexia \\ Code 6. Non-specific infection, not at \\ farrowing
}

Code 7. Abscesses/phlegmons

Code 8. Agalactia

Code 9. Reproduction disorder

Code 10. Diarrhoea

Code 11. Birth induction/prolonged pregnancy

Code 12. Abortion

Code 13. Hoof/joint diseases

Code 14. Deficiency diseases

Code 15. Respiratory diseases

Code 16. Erysipelas

Code 17. Skeletal/muscular disease

Code 18. Urinary tract diseases

Code 19. Other diseases

Diseases in piglets

Code 30. Neonatal diarrhoea

Code 31. Diarrhoea at $>1$ week of age

Code 32. Arthritis

Code 33. Skin diseases

Code 34. Respiratory diseases

Code 35. Other diseases in piglets

Congenital defects

Code 36. Splay-leg

Code 37. Cryptorchism

Code 38. Atresia ani

Code 39. Deformed or mummified piglets

Code 40. Umbilical hernia

Code 41. Scrotal hernia

Code 42. Shivering

Code 43. Hermaphrodism

Diseases in fatteners

Code 50. Diarrhoea

Code 51. Respiratory diseases

Code 52. Hoof/joint diseases

Code 53. Abscesses/phlegmons

Code 54. Tail biting/cannibalism

Code 55. Slow growing pigs

Code 56. Muscular degeneration

Code 57. Other diseases 
Table 3. The farmers' subjective opinion on the $\%$ recorded diseases on the health card.

\begin{tabular}{lrrrrrrrr}
\hline & \multicolumn{7}{c}{ No. of replies in each percentage group } \\
\cline { 2 - 9 } \% Diseases recorded & $>90$ & $80-90$ & $70-80$ & $60-70$ & $50-60$ & $<50$ & NR* $^{*}$ \\
\hline Diseases in the sow & 31 & 14 & 8 & 2 & & & \\
Diarrhoea in piglets & 22 & 9 & 7 & 2 & 1 & 13 & 1 \\
Arthritis in piglets & 15 & 9 & 9 & 7 & 2 & 13 & \\
Scrotal hernia & 22 & 9 & 8 & & 1 & 13 & 2 \\
Cryptorchism & 26 & 9 & 3 & 2 & 3 & 6 & 6 \\
\hline
\end{tabular}

${ }^{*} \mathrm{NR}=$ No reply.

Norwegian pig herd performance recording scheme, however, most of the breeding sows are well marked. This allows for easy control of the identity of sows, and of piglets until weaning. Because of difficulties with identification, diseases in slaughter pigs were not recorded. Diseases of slaughter pigs are, however, very important, and should be reported in the future. Based on experience gained from the health card project a new health card was designed. Though this health card was almost identical to the herd card used in the project, codes were added for recording diseases in slaughter pigs. The new health card is shown in Fig. 1b, the corresponding codes being provided in Table 2 .
As can be seen, diseases in sows and piglets are recorded on an individual basis, while diseases in slaughter pigs are recorded as the number of pigs treated instead of by individual numbers.

There was a satisfactory response to the questionnaires; replies were received from $55(79 \%)$ of the farmers and $9(90 \%)$ of the veterinarians. The replies of the farmers are summarized in Table 3.

It is obvious from Table 3 that disease recording is relatively good as regards the common diseases in sows and piglets treated by veterinarians. The replies from veterinarians correspond well with those from the farmers.

Table 4. An example of a herd disease report of the type sent to the farmers.

\begin{tabular}{|c|c|c|c|c|c|}
\hline \multicolumn{6}{|c|}{$\begin{array}{l}\text { THE FREQUENCY OF TREATMENTS PR. } 100 \text { SOWS DURING ONE YEAR } \\
\text { (Last quarter 09.15.85-12.25.85). }\end{array}$} \\
\hline \multirow[b]{2}{*}{ Disease category } & \multirow[b]{2}{*}{ (Tab. 1) } & \multicolumn{2}{|c|}{ Last quarter } & \multicolumn{2}{|c|}{ Previous year } \\
\hline & & $\begin{array}{l}\text { This } \\
\text { herd }\end{array}$ & $\begin{array}{c}\text { All } \\
\text { herds }\end{array}$ & $\begin{array}{l}\text { This } \\
\text { herd }\end{array}$ & $\begin{array}{c}\text { All } \\
\text { herds }\end{array}$ \\
\hline All diseases & $(5-45)$ & 103.5 & 57.5 & 137.7 & 47.2 \\
\hline Most important & $(10-33)$ & 69.0 & 54.6 & 105.3 & 41.6 \\
\hline Rec. by farmer & $(39-45)$ & 34.5 & 1.6 & 24.3 & 3.9 \\
\hline MMA-syndrome & $(11)$ & 20.7 & 23.4 & 27.0 & 16.4 \\
\hline Mastitis & (12) & 13.8 & 6.4 & 16.2 & 4.2 \\
\hline Metritis & (13) & 6.9 & 3.2 & 5.4 & 2.5 \\
\hline Neonatal diarrhoea & (30) & 6.9 & 5.2 & 2.5 & 4.2 \\
\hline Arthritis & (33) & 12.2 & 4.5 & 7.4 & 4.2 \\
\hline
\end{tabular}


An example of a herd disease report of the type sent to farmers is given in Table 4.

The disease reports which were sent to the veterinarians gave information on the same disease categories as those sent to the farmers, but with separate results for each herd. The results for the herd in Table 4 show that the herd in question had a higher frequency of recorded diseases compared to the overall disease frequency.

The opinion of the farmers and veterinarians of the feed-back system varied (Table 5).

Table 5. Subjective opinion on the value of the feed-back system.

\begin{tabular}{lcc}
\hline & Farmers & Veterinarians \\
\hline $\begin{array}{l}\text { No value } \\
\text { Valuable for special }\end{array}$ & 4 & - \\
situations & 17 & 5 \\
$\begin{array}{l}\text { Good help for evaluation } \\
\text { of problems }\end{array}$ & 32 & 4 \\
No reply & 2 & - \\
\hline
\end{tabular}

All of the veterinarians considered the feedback system to be of some value. Half of the veterinarians replied that the overview of diseases was valuable in special situations, while the other half considered the feed-back statistics to be a valuable tool in obtaining a general overview of the disease pattern in the district. Most of the farmers were satisfied with the feed-back system.

\section{Discussion}

Most of the entries on the health card are based on veterinary diagnosis. This was done to achieve a high reliability, as there is probably less divergence between veterinarians than between farmers regarding the definition of a disease. Some diseases must, however, of necessity be registered by the farmers, especially congenital defects, as well as diseases for which the veterinarian is not consulted. The simultaneous testing of the individual health card and the herd card, made the advantages of the herd card obvious. The system with a separate card for each animal, as practiced in Norwegian dairy cattle herds (Solbu 1983), gave a good documentation of the health status of the individual sow and its litter through several years. In this way it was possible to select the sows with low disease incidence for breeding purposes. However, it was difficult to get an overview over the disease incidence in the herds using individual health cards, and the high turnover rate of sows in the herds resulted in extra work to follow up the system. The herd card gave an overview of herd problems and was easy to follow up. These latter two factors were considered the most important, and were the main reasons for choosing the herd card.

Feed-back seems to be extremely important with regard to keeping the percentage of recorded diseases at an acceptable level. Disease recording will always require some extra effort, and it is therefore important to make the beneficial effects obvious both for the farmers and veterinarians. Farmers receive, however, a lot of reports during the year from different sources. The results from herd performance control are received most frequently, but data on disease recorded on post-mortem examination at the slaughterhouse are also sent to the farmer. Add to these the reports from the health card system, and it is obvious that there is a danger that the farmer will be inundated with reports which he will then ignore. It would therefore be a great advantage if the different information could be gathered in one single report. This would also allow an easier comparison of performance results with the disease records.

A disease recording system is a valuable aid in preventive veterinary medicine. Efficient use of the information generated depends on 
a rapid data flow from the herds to a central unit and back to the farmers and veterinarians. The system should also allow for generation of special disease reports. This would include instances as when there is a rapid increase in disease frequencies, when reduced feed conversion or growth rates are detected, or before visits to the herds. Breeders' associations and research institutions may also have access to necessary data for different purposes.

A central unit should collect data from the herd visits and receive information from slaughterhouses on frequencies of diseases found at post-mortem inspection. The reports to the farmers and veterinarians should contain information on herd performance, clinical disease and disease in carcasses and should be issued at least 4-6 times a year. In Norwegian herd performance recording scheme most of the information collected from the herds is entered into portable (hand-held) mini-computers, data subsequently being sent to the central unit via telephone lines. This permits disease reports to be issued within a week after the collection of disease data, optimal use of such information therefore being possible.

Treatment of pigs with drugs in the period prior to slaughter may sometimes result in the slaughter of animals containing drug residues. Such carcasses should be detected and condemned at meat inspection. Undetected, carcasses with drug residues may represent a public health problem. One important advantage of a health card system in this context is that it allows the use of drugs in a herd to be monitored by checking the health card before slaughter. The veterinarians and farmers considered the health card to be a valuable tool for this purpose.

The practical value of recording diseases for breeding purposes depends on the breeding system. In Norway, there is a single large artificial insemination centre for boars and about $70 \%$ of all sows in Norway are bred by artificial insemination. It would therefore be possible to obtain health records on a great number of offspring if disease recording were to be carried out in breeding herds and normal commercial herds. Even though the heritabilities for diseases generally are low, it should prove possible to get reliable information on the breeding value of boars with regard to the most common diseases.

\section{Conclusions}

Disease recording in pigs can be conveniently and efficiently implemented using herdhealth cards, and can provide information on diseases in sows, piglets and slaughter pigs. Diseases in sows and piglets can also be recorded on an individual basis. The individual recording of diseases in slaughter pigs would be necessary if genetical disease resistance were to be investigated, but is probably not realistic. Diseases in slaughter pigs are best recorded on a quantitative basis by herd.

Routine feed-back of results to farmers and veterinarians is important in keeping the percentage recorded diseases at an acceptable level. The reports should contain information on performance, clinical disease, and disease detected at meat inspection. Collection of data can be done using portable computers, a system which allows disease reports to be returned to the farmers and veterinarians quickly, preferably in less than 1 week. The disease reports containing information on both herd incidence and overall incidence in the district, were judged as useful both by farmers and veterinarians.

\section{Acknowledgements}

The investigation was supported by the Norwegian Pig Breeders' Association, and would not have been possible without excellent help from farmers and veterinarians in Hedmark. 


\section{References}

Anonymus: Husdyrkontrollen i Norge, 1985. Med statistikk fra kukontrollen, geitkontrollen, sauekontrollen og purkekontrollen. (The Norwegian herd performance recording scheme, 1985). Landsrådet for husdyrkontrollen 1986.

Solbu $H$ : Disease recording in Norwegian dairy cattle. I. Disease incidence and non-genetic effects on mastitis, ketosis and milk fever. $Z$. Tierz. Züchtungsbiol. 1983, 100, 139-157.

\section{Sammendrag}

Epidemiologiske og genetiske studier av sjukdommer i norske svinebesatninger. I.

Utformning av et praktisk registreringssystem.

Undersøkelsen bygger på sjukdomsregistreringer i 70 norske svinebesetninger fra 1984 til 1986 . Formålet var å konstruere et helsekort basert på individuelle sjukdomsregistreringer. Registreringene omfattet sjukdommer på purke og påsmågris fram til avvenning. Forsøket viste at oppfølging var viktig for å holde registreringene på et tilfredsstillende nivå. Det ble konkludert at individuelle registreringer på besetningskort var best egnet for innsamling av data for epidemiologiske og genetiske studier av sjukdommer hos svin.

(Received May 4, 1989; accepted November 13, 1989).

Reprints may be requested from: Frode Lingass, Department of Animal Genetics, Norwegian College of Veterinary Medicine, P. O. Box 8146 Dep., N-0033 Oslo 1, Norway. 